\title{
Assessing the effects of interventions for Aedes aegypti control: systematic review and meta-analysis of cluster randomised controlled trials
}

Víctor Alvarado-Castro ${ }^{1 *}$, Sergio Paredes-Solís ${ }^{1}$, Elizabeth Nava-Aguilera', Arcadio Morales-Pérez', Lidia Alarcón-Morales'ㄹ, Norma Alejandra Balderas-Vargas ${ }^{1}$ and Neil Andersson ${ }^{1,3}$

From The Camino Verde Trial colloquium

Acapulco, Mexico. 17-21 June 2013

\begin{abstract}
Background: The Aedes aegypti mosquito is the vector for dengue fever, yellow fever, chikungunya, and zika viruses. Inadequate vector control has contributed to persistence and increase of these diseases. This review assesses the evidence of effectiveness of different control measures in reducing Aedes aegypti proliferation, using standard entomological indices.
\end{abstract}

Methods: A systematic search of Medline, Ovid, BVS, LILACS, ARTEMISA, IMBIOMED and MEDIGRAPHIC databases identified cluster randomised controlled trials (CRCTs) of interventions to control Aedes aegypti published between January 2003 and October 2016. Eligible studies were CRCTs of chemical or biological control measures, or community mobilization, with entomological indices as an endpoint. A meta-analysis of eligible studies, using a random effects model, assessed the impact on household index $(\mathrm{HI})$, container index $(\mathrm{Cl})$, and Breteau index $(\mathrm{BI})$.

Results: From 848 papers identified by the search, eighteen met the inclusion criteria: eight for chemical control, one for biological control and nine for community mobilisation. Seven of the nine CRCTs of community mobilisation reported significantly lower entomological indices in intervention than control clusters; findings from the eight CRCTs of chemical control were more mixed. The CRCT of biological control reported a significant impact on the pupae per person index only. Ten papers provided enough detail for meta-analysis. Community mobilisation (four studies) was consistently effective, with an overall intervention effectiveness estimate of $-0.10(95 \% \mathrm{Cl}-0.20-0.00)$ for $\mathrm{HI},-0.03$ $(95 \% \mathrm{Cl}-0.05--0.01)$ for $\mathrm{Cl}$, and $-0.13(95 \% \mathrm{Cl}-0.22--0.05)$ for Bl. The single CRCT of biological control had effectiveness of $-0.02(95 \% \mathrm{Cl}-0.07-0.03)$ for $\mathrm{HI},-0.02(95 \% \mathrm{Cl}-0.04--0.01)$ for $\mathrm{Cl}$ and $-0.08(95 \% \mathrm{Cl}-0.15--0.01)$ for $\mathrm{Bl}$. The five studies of chemical control did not show a significant impact on indices: the overall effectiveness was -0.01 (95\% Cl -0.05-0.03) for $\mathrm{HI}, 0.01(95 \% \mathrm{Cl}-0.01-0.02)$ for $\mathrm{Cl}$, and 0.01 (95\% Cl $-0.03-0.05)$ for $\mathrm{Bl}$.

Conclusion: Governments that rely on chemical control of Aedes aegypti should consider adding community mobilization to their prevention efforts. More well-conducted CRCTs of complex interventions, including those with biological control, are needed to provide evidence of real life impact. Trials of all interventions should measure impact on dengue risk.

Keywords: Dengue, chemical control, biological control, community mobilisation, meta-analysis

\footnotetext{
* Correspondence: alvarado@cimat.mx

${ }^{1}$ Centro de Investigación de Enfermedades Tropicales (CIET), Universidad

Autónoma de Guerrero, Acapulco, Guerrero, Mexico

Full list of author information is available at the end of the article
} 


\section{Background}

In 2013, Bhatt and colleagues estimated 390 million dengue infections worldwide each year, with 96 million of these producing some clinical manifestation [1]. They estimated that Asia accounts for $70 \%$ of these infections, India alone accounting for 34\%; $14 \%$ occur in the Americas, more than half of which occur in Brazil and Mexico; $16 \%$ occur in Africa, and only $0.2 \%$ in Oceania [1]. Since publication of the articles in this review, a new dengue vaccine has been approved for use in Mexico [2], the Philippines [3] and Brazil [4]. Notwithstanding the new vaccine, vector control probably will remain an important element of dengue prevention and dengue prevention research [5, 6]. A World Health Organisation (WHO) meeting of experts in March 2016 noted, however, that there was no evidence that recent vector-control efforts such as massive use of insecticides have a significant effect on dengue transmission [7].

Aedes aegypti is an important vector for dengue virus infection. Apart from dengue virus, Aedes aegypti is also the vector for transmission of other viruses presenting serious public health threats: chikungunya [8, 9], zika [10] and yellow fever [11]. There is currently no vaccine available for chikungunya or zika. Following a big outbreak of zika in Brazil, including cases of microcephaly among babies born to infected mothers, WHO declared zika a public health emergency of international concern and issued a response framework and operations plan for tackling zika worldwide [12]. There is a huge shortfall in funding for the WHO response programme [13]; with limited funding there is an urgent need to identify the most effective interventions for Aedes aegypti vector control.

Summarised in Table 1, 12 systematic reviews synthesized evidence of the effectiveness of chemical, biological and community participation interventions for control of the Aedes aegypti vector and dengue infection [14-25]. These covered 278 studies with considerable overlap, including 26 cluster randomised controlled trials (CRCTs). The most common study design was a non-randomised controlled trial (110 studies), and before-after analysis (88 studies). Some reviews had a broad focus, covering multiple interventions $[15,17,24,25]$, others covered more specific community-based interventions [14, 19] or outbreak control [16]. Some were limited to single specific interventions, such as peridomestic spraying of insecticide [18], use of Bacillus thuringiensis israelensis [20], temephos [21], larvivorous fish [22] or copepods [23].

Several reviews concluded that some form of integrated vector management (IVM), including chemical control, community involvement, and co-operation between services was the best approach to reduce entomological indices of Aedes aegypti infestation or control outbreaks of dengue [15, 16, 24]. WHO recommends IVM for control of vector borne diseases, including dengue [26, 27].

The authors of many of the previous reviews noted that their conclusions were limited by the poor quality of the available evidence. Existing evidence studied impact mostly on vector indices rather than on dengue infection or disease incidence. While reviews suggested effectiveness of community involvement and mobilisation, the weak study designs and poor quality of reporting made interpretation difficult $[14,19]$. Reviews focusing on specific biological control methods were largely unable to conclude about effectiveness because the relatively few published studies generally had weak designs [20, 22, 23]. Reviews of specific chemical interventions were also limited in their conclusions. A review of 15 studies of peridomestic insecticide spraying included only one CRCT, the remainder using before-after analyses [18]. A review of 27 studies of the effectiveness of temephos for dengue control included only three CRCTs; the authors concluded there was evidence that temephos alone, although not in combination, suppressed entomological indices, but noted there was no evidence that temephos use was associated with decreased dengue transmission [21]. Authors of a 2009 review including multiple approaches for dengue control complained of the problems of poor study design and non-comparable entomological endpoints [17], and a recent review of the effects of multiple dengue prevention approaches noted a lack of reliable evidence of effectiveness, particularly on the endpoint of dengue incidence [25].

Review authors have repeatedly called for more cluster randomised controlled trials of single and combined interventions for dengue prevention, with measurement of their impact on dengue transmission as well as on vector indices $[17,22,25]$. The aim of the present study is to review the effectiveness of interventions for dengue vector control, specifically as measured in CRCTs. This limits the number of eligible studies, but means that the findings of those that are included are likely to be more reliable.

\section{Methods}

\section{Search strategy}

In 2013 we carried out a systematic search for articles published between January 2003 and June 2013 assessing the impact of chemical control, biological control and/or community mobilization as strategies for Aedes aegypti vector control. We searched the Medline, Ovid, BVS, LILACS, ARTEMISA, IMBIOMED and MEDIGRAPHIC databases. The search terms we used were "dengue", "Aedes aegypti", "chemical control", "biological control", "community-based", "community mobilisation", "social 
Table 1 Summary of systematic reviews on dengue vector control from 2007 to 2016

\begin{tabular}{|c|c|c|c|c|}
\hline Author and year & Focus of the review & $\begin{array}{l}\text { Number } \\
\text { of } \\
\text { studies }\end{array}$ & $\begin{array}{l}\text { Epidemiological design } \\
\text { of the included studies }\end{array}$ & Main conclusions \\
\hline Heintze (2007) [14] & $\begin{array}{l}\text { Community-based dengue } \\
\text { control interventions }\end{array}$ & 11 & $\begin{array}{l}2 \text { Randomized controlled trials } \\
3 \text { Interrupted time series } \\
6 \text { Before-after analysed trials }\end{array}$ & $\begin{array}{l}\text { Interventions and outcomes varied. } \\
\text { Six studies combined community } \\
\text { participation programmes with } \\
\text { dengue control tools. Only } 2 \text { papers } \\
\text { reported confidence intervals; } \\
5 \text { reported p-values; none were } \\
\text { cluster randomized. Weak evidence } \\
\text { that community-based programmes } \\
\text { alone or in combination can enhance } \\
\text { dengue control. }\end{array}$ \\
\hline
\end{tabular}

Erlanger (2008) [15] Effect of different dengue control methods on entomological indices in developing countries. (With meta-analysis)

Pilger (2008) [16] Response to dengue outbreaks

2 Cluster randomized control trials

Ballenger-Browning Impact of biological, chemical and educational interventions on entomological indices

Esu (2010) [18]

Effect of peridomestic insecticide spraying on dengue transmission

Al-Muhandis (2011) Impact of educational [19] messages and community based approach (With meta-analysis)

Boyce (2013) [20] Bacillus thuringiensis israelensis (Bti) for the control of dengue vectors

George (2015) [21] Community effectiveness of temephos for dengue control
273 Cluster randomized control trials 11 Non-randomized controlled trials 13 Before-after analysed trials 2 Randomized controlled trials 23 Non-randomized controlled trials and BI. Environmental management 2 Interrupted time series 24 Before-after analysed trials 3 Observational studies

Non-randomized controlled trials 2 Interrupted time series 4 Before-after analysed trials 14 Observational studies

$21 \quad 2$ Cluster randomized control trials 3 Randomized controlled trials 3 Interrupted time series, 13 Non-randomized controlled trials

Integrated vector management most alone relatively low effectiveness. Biological control targeted small numbers; IVM targeted larger populations. Most effective is a community-based, integrated approach, tailored and combined with educational programmes.

Combined interventions of vector control (community involvement \& use of insecticides), training of medical personnel, plus laboratory support, helped control outbreaks. Spatial spraying of insecticides alone ineffective and its usefulness with other interventions is doubtful.

Evidence of efficacy lacking: poor study designs and lack of congruent entomologic indices. Need more cluster randomized controlled trials.

151 Cluster randomized control trial 14 Before-after analysed trials

Few studies of effectiveness of peri-domestic space spraying. Best applied as part of IVM. Need to measure impact of spraying on adult and immature mosquitoes and disease transmission.

Important impact of educational messages in a community-based approach on larval indices. Very heterogeneous effect size with different study designs; interpretation of pooled results difficult.

2 Cluster randomized control trials 1 Randomized controlled trial

11 Non-randomized controlled trials

Bti can reduce the number of immature Aedes in the short term, but very limited evidence that Bti alone can reduce dengue morbidity. Need to measure impact of Bti in combination with other strategies to control dengue vectors.

Temephos alone suppressed entomological indices; did not do so when combined with other interventions. No evidence that temephos use is associated with reduced dengue transmission. 
Table 1 Summary of systematic reviews on dengue vector control from 2007 to 2016 (Continued)

\begin{tabular}{|c|c|c|c|c|}
\hline Han (2015) [22] & $\begin{array}{l}\text { Efficacy and community } \\
\text { effectiveness of larvivorous } \\
\text { fish for dengue vector control }\end{array}$ & 13 & $\begin{array}{l}9 \text { Non-randomized controlled trials } \\
4 \text { Before-after analysed trials }\end{array}$ & $\begin{array}{l}\text { Larvivorous fish alone or combined } \\
\text { with other control measures may } \\
\text { reduce immature vector stages. } \\
\text { Study limitations preclude conclusions } \\
\text { about community effectiveness. Need } \\
\text { cluster randomised controlled trials } \\
\text { with measurement of impact on } \\
\text { dengue transmission }\end{array}$ \\
\hline Lazaro (2015) [23] & $\begin{array}{l}\text { Community effectiveness of } \\
\text { copepods for dengue vector } \\
\text { control }\end{array}$ & 11 & 11 Non-randomized controlled trials & $\begin{array}{l}\text { Limited evidence of impact of } \\
\text { cyclopoid copepods as a single } \\
\text { intervention. Very few studies; more } \\
\text { needed in other communities and } \\
\text { environments. }\end{array}$ \\
\hline Lima (2015) [24] & $\begin{array}{l}\text { Impact of chemical, physical } \\
\text { and biological control } \\
\text { (With meta analysis) }\end{array}$ & 26 & $\begin{array}{l}6 \text { Cluster randomized control trials } \\
16 \text { Non-randomized controlled trials, } \\
4 \text { Before-after analysed trials }\end{array}$ & $\begin{array}{l}\text { The most effective control method } \\
\text { was IVM, starting with community } \\
\text { empowerment as active agents of } \\
\text { vector control. }\end{array}$ \\
\hline $\begin{array}{l}\text { Bowman (2016) } \\
{[25]}\end{array}$ & $\begin{array}{l}\text { Effectiveness of different } \\
\text { control methods, alone and in } \\
\text { combination, on vector indices } \\
\text { and dengue transmission } \\
\text { (With meta analysis) }\end{array}$ & 39 & $\begin{array}{l}7 \text { Cluster randomized control trials } \\
2 \text { Randomized controlled trials } \\
8 \text { Non-randomized controlled trials } \\
11 \text { Interrupted time series } \\
5 \text { Before-after analysed trials } \\
6 \text { Observational studies }\end{array}$ & $\begin{array}{l}\text { Lack of reliable evidence on the } \\
\text { effectiveness of any dengue vector } \\
\text { control method. High quality studies } \\
\text { (such as CRCTs) are needed, with } \\
\text { measurement of effect on dengue } \\
\text { transmission as well as vector indices. }\end{array}$ \\
\hline
\end{tabular}

Total of 278 studies reviewed (with considerable overlap): 26 CRCTs; 10 RCTs; 110 non-randomised controlled trials; 21 interrupted time series; 88 before-after analyses; 23 observational studies

mobilisation", "community empowerment", "effectiveness" and "vector control", and their Spanish and Portuguese equivalents. We updated the search in November 2016 to cover articles published up to the end of October 2016. We also reviewed the references listed in identified publications and included additional studies found in these lists, limiting our search to publications in English, Spanish or Portuguese.

Figure 1 is a flow chart of the studies identified and finally included in the systematic review and meta analysis. The first search in 2013 produced a list of 588 articles. In 2015, we added a further 27 studies and in 2016 we added a further 233 studies identified by a new electronic search and a manual search (total 848 articles). Two reviewers (VA and LA), working

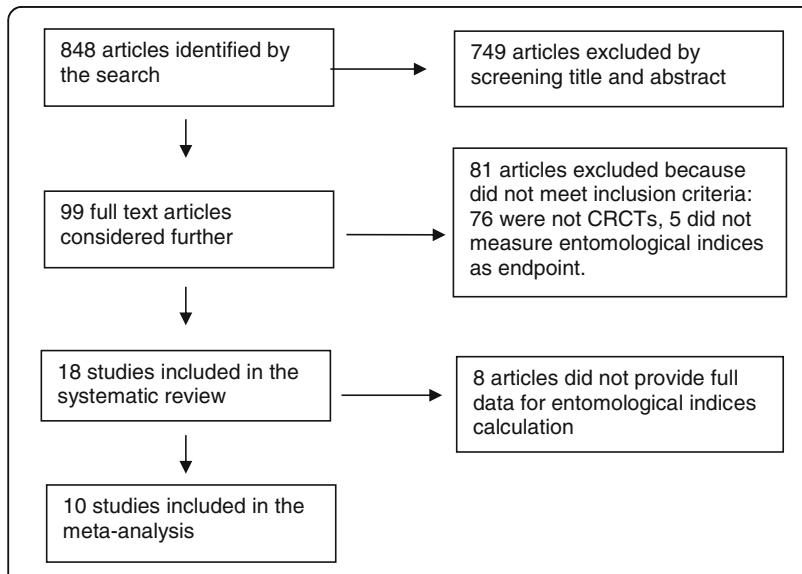

Fig. 1 Flow chart of studies included in the meta-analysis independently, reviewed the title and abstract of these articles. They excluded 749 articles: 590 because they clearly did not meet the inclusion criteria, and 159 because they were further publications of the same studies.

The pre-established inclusion criteria were:

- studies concerned directly with the impact of chemical control, biological control or community mobilisation, alone or in combination, on dengue vector parameters;

- studies that were cluster randomized controlled trials; and

- studies that provided information about at least one of the three standard Aedes aegypti indices: house index (HI) - households with larvae or pupae as a proportion of households examined; container index (CI) - containers with larvae or pupae as a proportion of containers examined; and Breteau index (BI) - containers with larvae or pupae as a proportion of households examined.

The reviewers read the full text of the remaining 99 candidate articles and excluded 81 of them as not meeting the inclusion criteria. Five of the excluded studies did not measure impact on entomological indices, and 76 were not CRCTs. This systematic review includes all 18 remaining articles; 10 of these had the necessary information for calculation of the entomological indices to allow us to include them in the meta-analysis. 


\section{Data extraction and quality assessment}

We extracted data from the 18 articles using a format developed by consensus among study team members. Two reviewers extracted the data independently and then resolved discrepancies by consensus. We assessed methodological validity of the studies using the Cochrane approach for assessing the risk of bias [28]. This includes an assessment of how the studies handled and reported: random sequence generation, blinding of participants and personnel, blinding of outcome assessment, handling of incomplete data, and selectiveness of reporting. We graded each paper for each domain as having low, unclear or high risk of bias, and then calculated an overall risk of bias.

\section{Meta-analysis}

We defined intervention effectiveness for each of the entomological indices (HI, CI and $\mathrm{BI}$ ) as the difference between the intervention group and the control group at the last point of measurement. For each type of intervention (chemical control, biological control, community mobilisation) we performed a metaanalysis using a random effects model to estimate global intervention effectiveness for each entomological index (HI, CI, BI), estimating the combined overall Risk Difference (RD) and its 95\% CI. The model took into account inter- and intra-study variability by weighting [29]. We carried out the analysis using the open-source software CIETmap [30] and the "meta" package of the statistical language $\mathrm{R}$ [31].

We performed the DerSimonian and Laird Q test [32] to assess the level of heterogeneity, with the null hypothesis of non-heterogeneity. We derived $p$-values for this test by comparing the $\mathrm{Q}$ statistic with the $\alpha$-percentile of a $\chi^{2}$ distribution with $k-1$ degrees of freedom (where $k$ is the number of studies).

For each type of intervention, we measured each study's influence on the overall estimated intervention effectiveness by replicating the meta-analysis for each of the three entomological indices, eliminating one of the included studies from the analysis at each step. We then quantified the differences in the overall results $[29,33]$.

We assessed publication bias using a funnel plot, which shows the sample size of each study next to the detected effect size. We used the Begg and Egger statistical test $[34,35]$ and considered $p<0.10$ to be a statistically significant indicator of publication bias.

\section{Results}

Table 2 shows details of the 18 CRCTs that met our inclusion criteria for the review [36-53]. Published between January 2003 and December 2015, these studies all implemented interventions and measured impact at the cluster level. The 18 studies covered 246 intervention clusters (48,131 intervention households) and 288 control clusters $(69,430$ control households) in 13 countries: India, Thailand, Sri Lanka, Cuba, Haiti, Mexico, Guatemala, Nicaragua, Venezuela, Brazil, Uruguay, Ecuador and Colombia. Of the 18 CRCTs, we categorised eight as trials of chemical control interventions, one as a trial of a biological control method, and nine as trials of community mobilisation for dengue prevention.

Table 3 shows the risk of bias assessments for the 18 studies. We assessed eight studies as having a low risk of bias overall, the remaining 10 having an unclear risk of bias mainly because they did not provide enough information to assess some elements of the risk of bias.

\section{Chemical control interventions}

Among the eight CRCTs categorised as chemical control interventions, five tested the effect of insecticide-treated window and door screens or curtains: one as a single intervention [41], two combined with insecticide-treated water container covers [37, 42], and two combined with temephos or spinosad treatment of productive water containers $[40,43]$. One trial tested the impact of insecticide-treated bed nets as a single intervention [38] and one tested the impact of temephos applied to water containers as a single intervention [36]. Ocampo et al. reported on a trial of lethal ovitraps and Bacillus thuringiensis israelensis (Bti) briquettes, alone or in combination, together with an initial education and clean-up campaign and regular household visits. Since education/ clean-up and visits alone was also the 'control' condition, we categorised this as a chemical intervention of the deltamethrin lethal ovitraps [39]. Three trials had a staged intervention: in Guatemala deltamethrin-treated window and door nets were replenished and supplemented with temephos treatment of productive containers after 17 months [40]; in Colombia, deltamethrin treated container covers supplemented deltamethrin treated window and door nets after eight months in about half the clusters [42]; and in Mexico, researchers added spinosad treatment of productive water containers to cypermethrin treated door and window screens after 14 months.

The number of clusters randomised to intervention and control status varied widely, from just one very large intervention and one very large control cluster in Brazil [36] to 22 intervention and 66 small control clusters in Thailand [41]. The largest number of households to receive the intervention was also in Thailand, although the researchers only measured entomological indices in half of these [41]. The duration of follow up varied from six weeks to 18 months after the start of an intervention. In the three studies with two-staged interventions, the last measurements of entomological indices were at six weeks $[40,42]$ to 10 months [43] after the second 


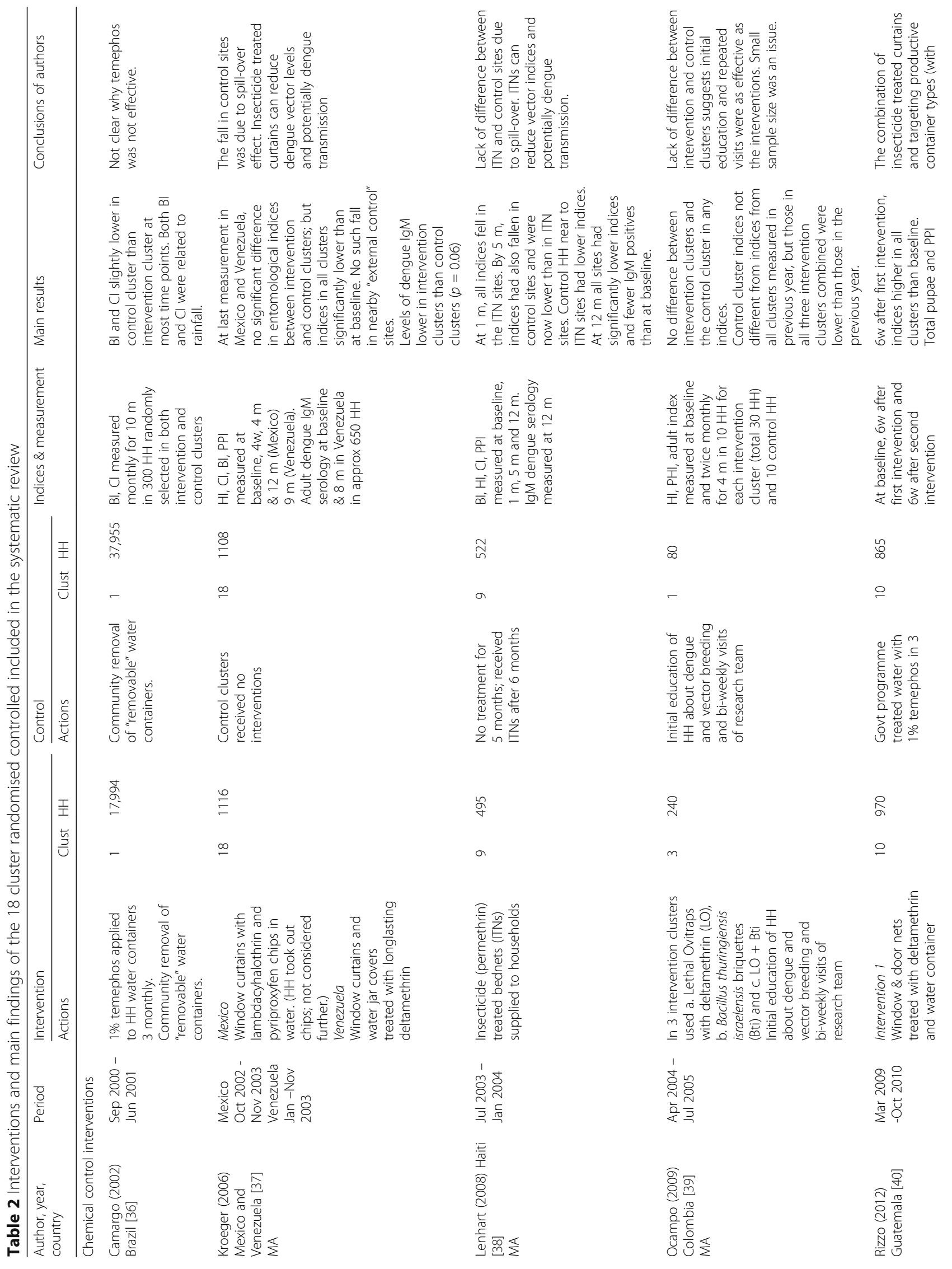




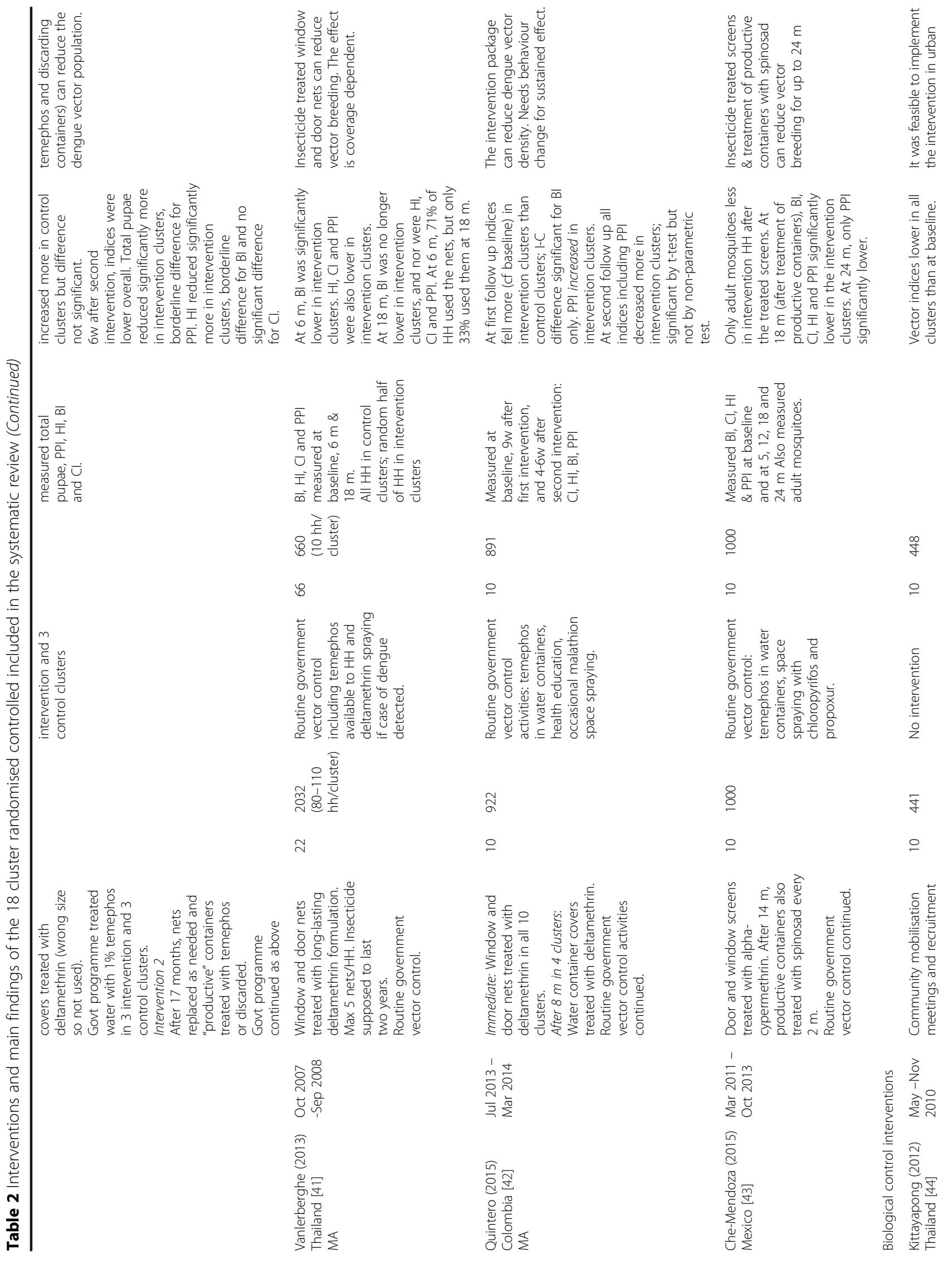




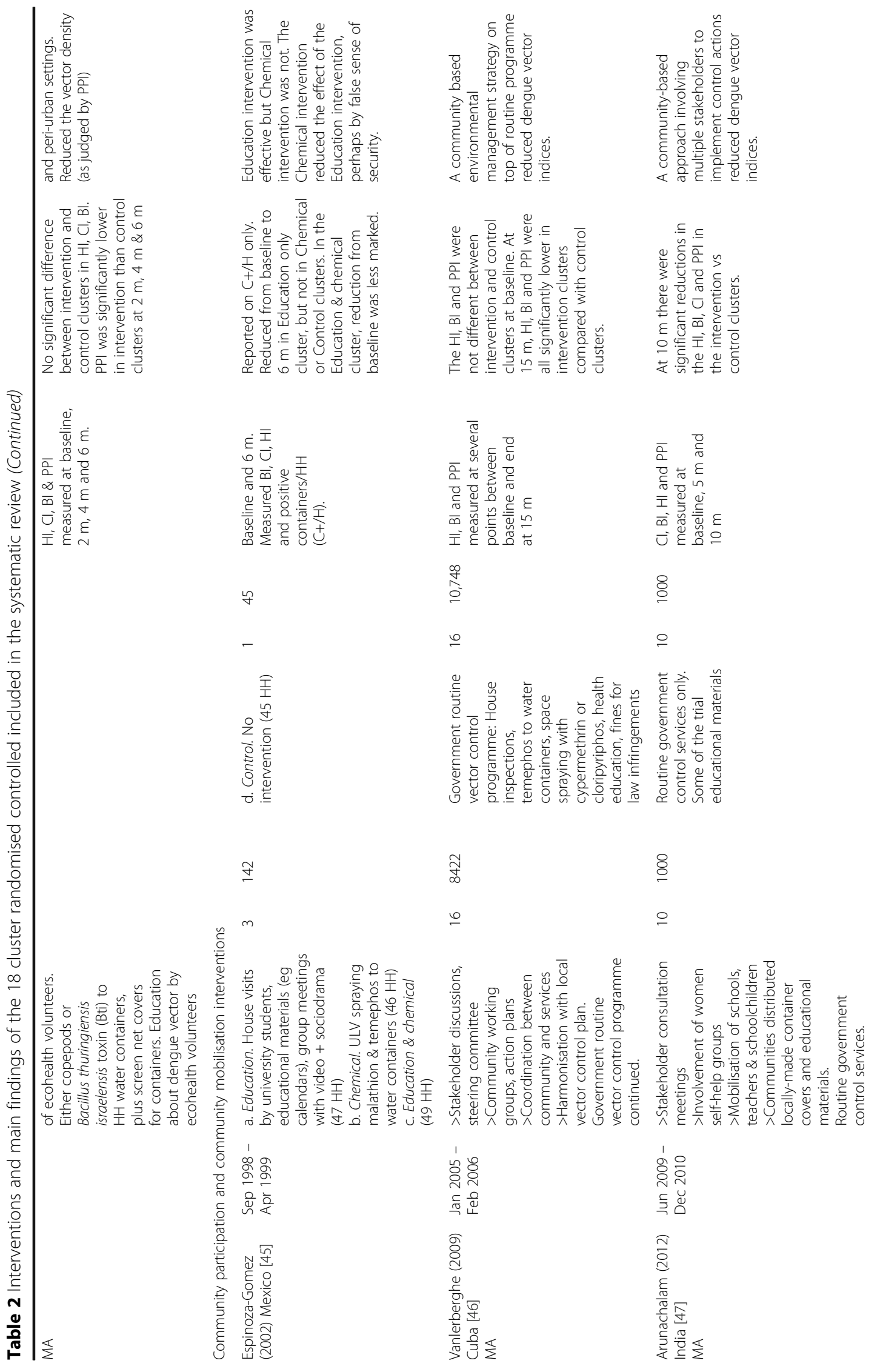




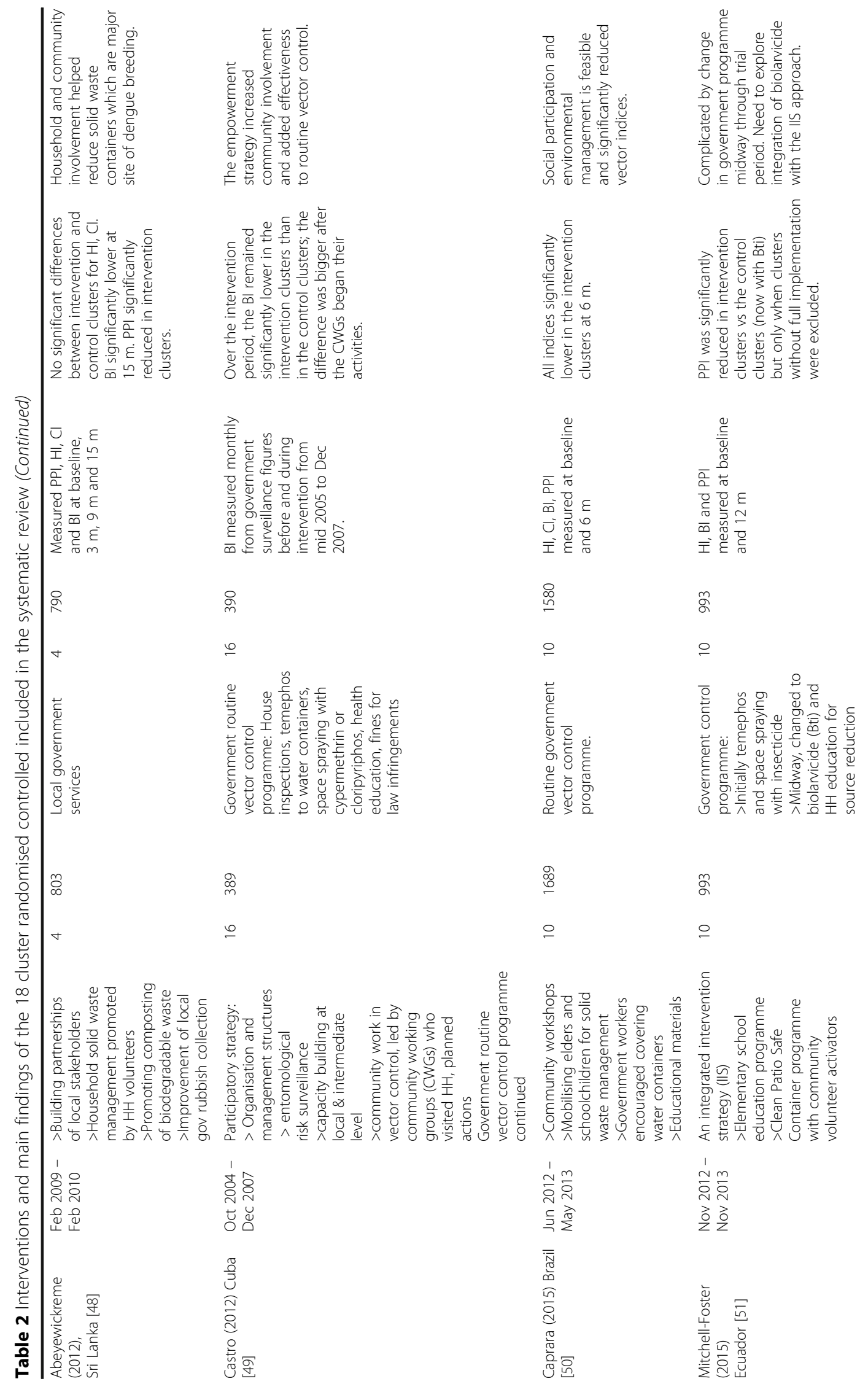




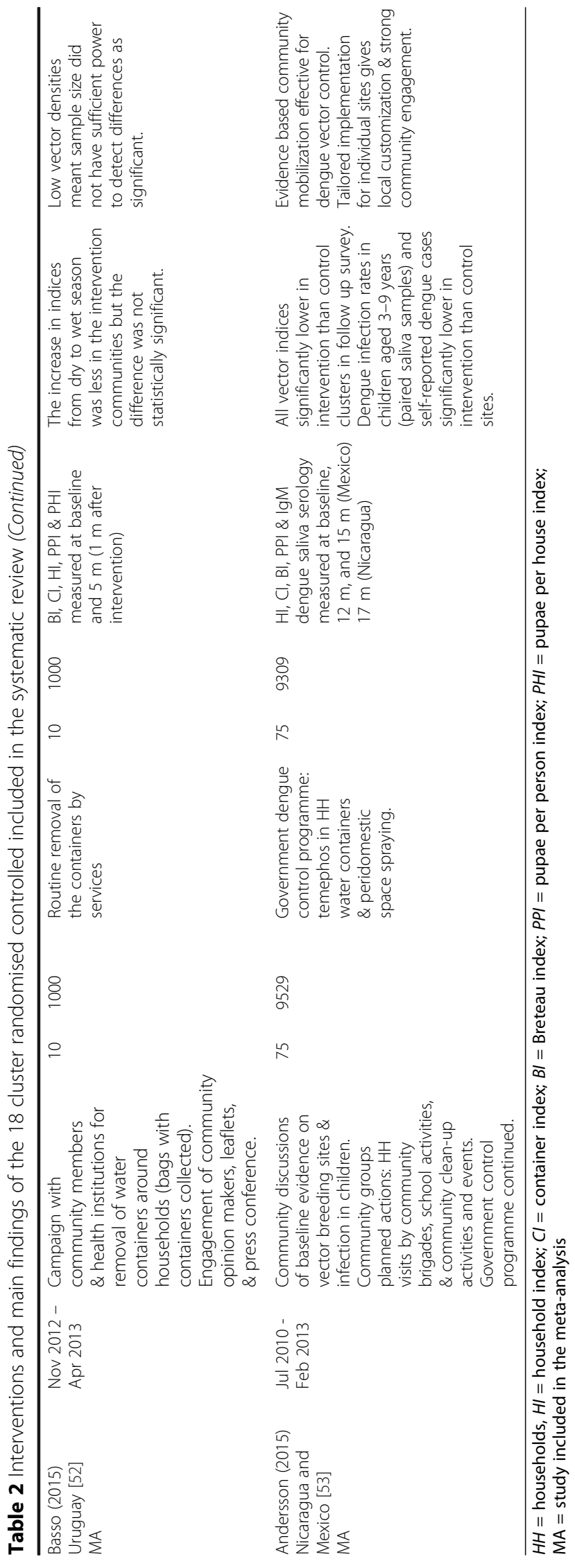


Table 3 Risk of bias assessment for the 18 studies, using Cochrane method

\begin{tabular}{|c|c|c|c|c|c|c|c|}
\hline First author \& year & Intervention & $\begin{array}{l}\text { Blinding of } \\
\text { participants \& } \\
\text { personnel }\end{array}$ & $\begin{array}{l}\text { Blinding of } \\
\text { outcome } \\
\text { assessment }\end{array}$ & $\begin{array}{l}\text { Incomplete } \\
\text { outcome } \\
\text { data }\end{array}$ & $\begin{array}{l}\text { Selective } \\
\text { reporting }\end{array}$ & $\begin{array}{l}\text { Other } \\
\text { sources } \\
\text { of bias }\end{array}$ & $\begin{array}{l}\text { Summary of risk of } \\
\text { bias assessment }{ }^{\mathrm{a}}\end{array}$ \\
\hline Camargo (2002) [36] & Chemical control & 1 & 2 & 2 & 2 & 2 & 2 \\
\hline Kroeger (2006) MA [37] & Chemical control & 1 & 2 & 1 & 1 & 2 & 1 \\
\hline Lenhart (2008) MA [38] & Chemical control & 1 & 2 & 2 & 2 & 2 & 2 \\
\hline Ocampo (2009) MA [39] & Chemical control & 1 & 2 & 2 & 1 & 2 & 2 \\
\hline Rizzo (2012) [40] & Chemical control & 1 & 2 & 2 & 1 & 2 & 2 \\
\hline Vanlerberghe (2013) MA [41] & Chemical control & 1 & 2 & 1 & 1 & 2 & 1 \\
\hline Quintero (2015) MA [42] & Chemical control & 1 & 2 & 1 & 1 & 2 & 1 \\
\hline Che-Mendoza (2015) [43] & Chemical control & 1 & 2 & 2 & 1 & 2 & 2 \\
\hline Kittayapong (2012) MA [44] & Biological control & 1 & 2 & 2 & 1 & 2 & 2 \\
\hline Espinoza-Gomez (2002) [45] & Community participation & 1 & 2 & 2 & 1 & 2 & 2 \\
\hline Vanlerberghe (2009) MA [46] & Community participation & 1 & 2 & 1 & 1 & 2 & 1 \\
\hline Arunachalam (2012) MA [47] & Community participation & 1 & 2 & 1 & 1 & 2 & 1 \\
\hline Abeyewickreme (2012) [48] & Community participation & 1 & 2 & 2 & 2 & 2 & 2 \\
\hline Castro (2012) [49] & Community participation & 1 & 2 & 1 & 1 & 2 & 1 \\
\hline Caprara (2015) [50] & Community participation & 1 & 2 & 2 & 1 & 2 & 2 \\
\hline Mitchell-Foster (2015) [51] & Community participation & 1 & 2 & 1 & 1 & 2 & 1 \\
\hline Basso (2015) MA [52] & Community participation & 1 & 2 & 2 & 1 & 2 & 2 \\
\hline Andersson (2015) MA [53] & Community participation & 1 & 1 & 1 & 1 & 2 & 1 \\
\hline
\end{tabular}

$1=$ Low risk of bias; $2=$ Unclear risk of bias; $3=$ High risk of bias.

${ }^{\text {a }}$ The summary figure is the median of the five individual elements

$M A=$ Included in the meta-analysis

intervention. For interventions beginning at single time point, the last measurements were at between four months [39] and 18 months [41].

Measured impacts of the interventions varied considerably. The temephos trial found no effect; the BI and CI were slightly lower in control than intervention clusters at most time points [36]. In the trials concerned with insecticide-treated window and door screens or curtains, three found an impact on pupal densities and other indices mainly after addition of the second intervention of treating productive containers [40,43] or of adding treated container covers [42]. The trial of treated door and window nets alone found that the impact on BI at six months, when $71 \%$ of households used the nets, was not maintained at 18 months, when only a third of households used the nets [41]. In the report of the trial of treated window and door nets in Mexico and Venezuela, with added treated container covers in Venezuela only, the authors found a reduction in entomological indices in all clusters, not different between intervention and control clusters, and attributed this to a spill-over into the nearby control clusters. The authors of the Haiti treated bed nets trial also attributed the fall in indices in all clusters, with no difference between intervention and control clusters, to a spill-over effect. The trial of deltamethrin lethal ovitraps and Bti, alone and in combination, with education and household visits as the control condition, found no difference in entomological indices between the intervention clusters and the control cluster. The authors postulated this could be because the initial education and clean-up followed by repeated visits were in themselves an intervention as effective as the interventions being tested [39].

Only two of the CRCTs measured the impact of chemical interventions on dengue infection as well as on entomological indices, with inconclusive findings. In the trial of deltamethrin treated window curtains and container covers in Venezuela, Kroeger et al. reported that positive adult dengue IgM serology at eight months was lower in intervention than control clusters, with borderline statistical significance [37]. In the trial of treated bed nets in Haiti, in all clusters there were fewer individuals positive for dengue IgM at 12 months; the authors considered the lack of difference between intervention and control clusters reflected a spill-over effect.

\section{Biological control interventions}

Only one study of a biological control cluster trial met the inclusion criteria. Kittayapong et al. in Thailand of using either copepods or Bti (the households had a choice) in household water containers to control breeding of the dengue vector [44]. The intervention also 
included community mobilisation meetings and recruitment of eco-health volunteers (EHVs) from among existing community health volunteers. The EHVs visited households to deliver the biological control materials and educated household members on elimination of vector breeding sites. Public services cleaned up communal spaces in the communities. Although there was also an element of community mobilisation, we categorised this trial as primarily of the biological control methods. The study compared 10 intervention clusters with 10 control clusters, with measurements of vector indices up to six months. The HI, CI and BI were significantly lower at follow up than at baseline in all clusters, but not so in control compared with intervention clusters. The PPI was significantly lower in intervention than control clusters at all time points after the baseline.

\section{Community mobilisation and participation interventions}

We categorised nine CRCTs as primarily trials of community mobilisation and participation, seven from Central and South America [45, 46, 49-53] and two from Asia [47, 48]. One trial from Mexico measured the impact of an educational intervention at household and community level and a chemical intervention (space spraying with malathion and temephos applied to household water containers), alone or in combination, compared with a control cluster with neither intervention [45]. Common features of the complex interventions included: engagement of local stakeholders in discussions of the problems and planning of activities; involvement of community members in prevention and dissemination activities; household visits to support their efforts to reduce dengue breeding sites; educational programmes at household and community levels; partnerships with local services; and efforts to improve local services such as garbage collection. Four trials involved schools and schoolchildren $[47,50,51,53]$ or elders [50]. Two noted the importance of involving women $[47,53]$. Specific activities included: distribution of locally made covers for water containers [47], promoting composting of biodegradable waste [48], and collecting small waste items from around houses [52].

In all trials, the routine government dengue control activities continued in the intervention as well as control clusters, so the measured impact was of the community mobilisation in addition to the routine prevention activities. In the trial from Ecuador [51], the analysis was complicated by a change in the government programme midway through the intervention: from a programme based on temephos in water and insecticide space spraying to use of a biolarvicide (Bti) and education for source reduction.

The included CRCTs varied in size, from a very small study in Mexico with three intervention clusters and one control cluster and a total of 187 households [45], and a small study in Sri Lanka with four intervention and four control clusters and 1593 households [48], to a study in Cuba with 16 intervention and 16 control clusters and a total of 19,170 households [46], and a trial in Nicaragua and Mexico with 75 intervention and 75 control clusters and a total of 18,838 households [53]. Length of follow up varied from five months $[45,50,52]$ to 24 months [49]. Some trials reported only measurements at baseline and follow up [45, 50-52], while others made one or more measurements in between $[46-48,53]$. One trial in Cuba relied on monthly measurements by the government vector control programme [49].

The reported impacts of the CRCTs varied but were broadly positive, with a significant impact on at least one entomological index. Four studies found all the measured indices were significantly lower in the intervention than control clusters at the last follow up $[46,47,50,53]$. The trial from Sri Lanka with a focus on solid waste management found a significant impact on BI at 15 months and on PPI at all time points [48]. The trial in Cuba that used figures from the routine government surveillance found significantly lower BI in intervention clusters at all time points [49]. The Ecuador trial of the elementary school education programme and the clean patio safe container programme detected a significant impact on PPI only at 12 months, but only when clusters without full implementation were excluded. This trial was complicated by the change (probably improvement) in the government programme in the control sites midway through the intervention [51]. The Uruguay trial reported a non-significant difference between intervention and control cluster in favour of the intervention; low vector densities in the sites reduced the power of the study to detect significant differences [52]. The small complicated trial from Mexico compared an educational intervention, with or without malathion spraying, with a control cluster. It found a significant impact of the education programme only on a specific index (positive containers per household); this impact was less marked when the education intervention was combined with malathion space spraying [45].

Only one CRCT of community mobilisation measured the impact on dengue infection. The trial in Nicaragua and Mexico found a significant impact on childhood dengue infection (assessed by dengue antibodies in paired saliva samples) and on self-reported dengue cases in households [53].

\section{Meta-analysis}

We assessed six studies in the meta-analysis as having a "low risk of bias" and four as having an "unclear risk of 
bias", because they did not report some of the information needed to assess elements of the risk of bias (Table 3).

Eight of ten articles in the meta-analysis provided the necessary data to calculate the combined effectiveness for all three entomological indices (HI, CI and $\mathrm{BI}$ ). One study provided information for only two indices (HI and BI) and one provided information only for the HI. Table 4 summarizes the data for the Aedes aegypti indices in the last measurement for each study's intervention and control groups, with calculated intervention effectiveness estimates (RD and 95\% CI). In every trial of community participation, the estimated intervention effectiveness was positive, showing a decrease in the $\mathrm{HI}, \mathrm{CI}$ and $\mathrm{BI}$; the higher $95 \%$ CI limit for these estimations is 0.03 (for the $\mathrm{HI}$ and $\mathrm{BI}$ ), from the study by Basso et al. in Uruguay [52].

The overall intervention impact assessments for the Household Index were -0.01 (95\% CI -0.05 to 0.03 ) for chemical control, and -0.10 (95\% CI -0.20 to 0.00 ) for community participation (Fig. 2). None of the confidence intervals for impact on $\mathrm{HI}$ from the studies of community participation interventions included unity, reflecting a consistently significant impact on this index. The single CRCT of biological control reported an impact of -0.02 ( $95 \% \mathrm{CI}-0.07$ to 0.03$)$ on the HI.
For the Container Index, community participation interventions again showed the most consistent impact. The overall intervention impact assessments for CI were 0.01 (95\%CI -0.01 to 0.02 ) for chemical control interventions, and -0.03 (95\%CI -0.05 to -0.01 ) for community participation interventions (Fig. 3). The single CRCT of biological intervention reported an impact of -0.02 (95\%CI -0.04 to -0.01 ) on the CI.

The estimated combined intervention impact of chemical control on the Breteau Index was 0.01 (95\% CI -0.03 to 0.05 ), while that of community participation was -0.13 (95\% CI -0.22 to -0.05$)$ (Fig. 4). The impact on $\mathrm{BI}$ of the single biological control trial was -0.08 (95\% CI -0.15 to -0.01 ).

We found significant heterogeneity ( $\mathrm{p}$-value $<0.001$ ) between the included studies for each of the entomological indices (HI, CI, BI) for both chemical control CRCTs and community mobilisation CRCTs. For both chemical control studies and community mobilisation studies, sensitivity analysis showed that no study, when it was excluded from the meta- analysis, substantially changed the overall outcome for any of the indices. We found no statistical evidence of publication bias; all the $p$ values obtained from the Begg and Egger test were 0.10 or greater, and nearly all were greater than 0.18 .

Table 4 Intervention effectiveness on dengue vector control of studies in meta-analysis

\begin{tabular}{|c|c|c|c|c|c|c|}
\hline First author \& year & $\begin{array}{l}\text { Time to impact } \\
\text { measurement (months) }\end{array}$ & Intervention type & Parameters & $\begin{array}{l}\text { Intervention } \\
\text { clusters }\end{array}$ & $\begin{array}{l}\text { Control } \\
\text { clusters }\end{array}$ & $\begin{array}{l}\text { Intervention effectiveness } \\
\text { (RD and } 95 \% \mathrm{Cl} \text { ) }\end{array}$ \\
\hline Kroeger (2006) & $\begin{array}{l}\text { Mexico } 9 \\
\text { Venezuela } 12\end{array}$ & Chemical control & $\begin{array}{l}\mathrm{HI} \\
\mathrm{Cl} \\
\mathrm{Bl}\end{array}$ & $\begin{array}{l}0.09 \\
0.01 \\
0.11\end{array}$ & $\begin{array}{l}0.12 \\
0.02 \\
0.14\end{array}$ & $\begin{array}{l}-0.03(-0.06 ; 0.00) \\
-0.01(-0.02 ; 0.00) \\
-0.03(-0.06 ; 0.00)\end{array}$ \\
\hline Lenhart (2008) & 5 & Chemical control & $\begin{array}{l}\mathrm{HI} \\
\mathrm{Cl} \\
\mathrm{Bl}\end{array}$ & $\begin{array}{l}0.05 \\
0.02 \\
0.06\end{array}$ & $\begin{array}{l}0.03 \\
0.01 \\
0.03\end{array}$ & $\begin{array}{l}0.02(-0.01 ; 0.05) \\
0.01(0.00 ; 0.19) \\
0.03(0.00 ; 0.06)\end{array}$ \\
\hline Ocampo (2009) & 15 & Chemical control & $\mathrm{HI}$ & 0.00 & 0.05 & $-0.05(-0.10 ; 0.00)$ \\
\hline Vanlerberghe (2013) & 12 & Chemical control & $\begin{array}{l}\mathrm{HI} \\
\mathrm{Cl} \\
\mathrm{BI}\end{array}$ & $\begin{array}{l}0.14 \\
0.66 \\
0.22\end{array}$ & $\begin{array}{l}0.19 \\
0.55 \\
0.24\end{array}$ & $\begin{array}{l}-0.05(-0.09 ;-0.01) \\
0.11(-0.04 ; 0.19) \\
-0.02(-0.06 ; 0.02)\end{array}$ \\
\hline Quintero (2015) & 8 & Chemical control & $\begin{array}{l}\mathrm{HI} \\
\mathrm{Cl} \\
\mathrm{Bl}\end{array}$ & $\begin{array}{l}0.07 \\
0.02 \\
0.07\end{array}$ & $\begin{array}{l}0.03 \\
0.01 \\
0.03\end{array}$ & $\begin{array}{l}0.04(0.02 ; 0.07) \\
0.01(0.00 ; 0.02) \\
0.04(0.02 ; 0.07)\end{array}$ \\
\hline Kittayapong (2012) & 8 & Biological control & $\begin{array}{l}\mathrm{HI} \\
\mathrm{Cl} \\
\mathrm{Bl}\end{array}$ & $\begin{array}{l}0.12 \\
0.03 \\
0.25\end{array}$ & $\begin{array}{l}0.14 \\
0.05 \\
0.33\end{array}$ & $\begin{array}{l}-0.02(-0.07 ; 0.03) \\
-0.02(-0.04 ;-0.01) \\
-0.08(-0.15 ;-0.01)\end{array}$ \\
\hline Vanlerberghe (2009) & 12 & Community participation & $\begin{array}{l}\mathrm{HI} \\
\mathrm{BI}\end{array}$ & $\begin{array}{l}0.26 \\
0.28\end{array}$ & $\begin{array}{l}0.48 \\
0.52\end{array}$ & $\begin{array}{l}-0.22(-0.23 ;-0.21) \\
-0.24(-0.25 ;-0.23)\end{array}$ \\
\hline Arunachalam (2012) & 18 & Community participation & $\begin{array}{l}\mathrm{HI} \\
\mathrm{Cl} \\
\mathrm{BI}\end{array}$ & $\begin{array}{l}0.04 \\
0.01 \\
0.04\end{array}$ & $\begin{array}{l}0.16 \\
0.06 \\
0.21\end{array}$ & $\begin{array}{l}-0.12(-0.15 ;-0.09) \\
-0.05(-0.06 ;-0.04) \\
-0.17(-0.20 ;-0.14)\end{array}$ \\
\hline Basso (2015) & 6 & Community participation & $\begin{array}{l}\mathrm{HI} \\
\mathrm{Cl} \\
\mathrm{Bl}\end{array}$ & $\begin{array}{l}0.07 \\
0.07 \\
0.12\end{array}$ & $\begin{array}{l}0.07 \\
0.08 \\
0.14\end{array}$ & $\begin{array}{l}0.00(-0.03 ; 0.03) \\
0.00(-0.03 ; 0.02) \\
-0.01(-0.06 ; 0.03)\end{array}$ \\
\hline Andersson (2015) & $\begin{array}{l}\text { Nicaragua } 32 \\
\text { Mexico } 32\end{array}$ & Community participation & $\begin{array}{l}\mathrm{HI} \\
\mathrm{Cl} \\
\mathrm{Bl}\end{array}$ & $\begin{array}{l}0.14 \\
0.05 \\
0.20\end{array}$ & $\begin{array}{l}0.20 \\
0.08 \\
0.30\end{array}$ & $\begin{array}{l}-0.06(-0.07 ;-0.05) \\
-0.03(-0.03 ;-0.02) \\
-0.10(-0.12 ;-0.09)\end{array}$ \\
\hline
\end{tabular}




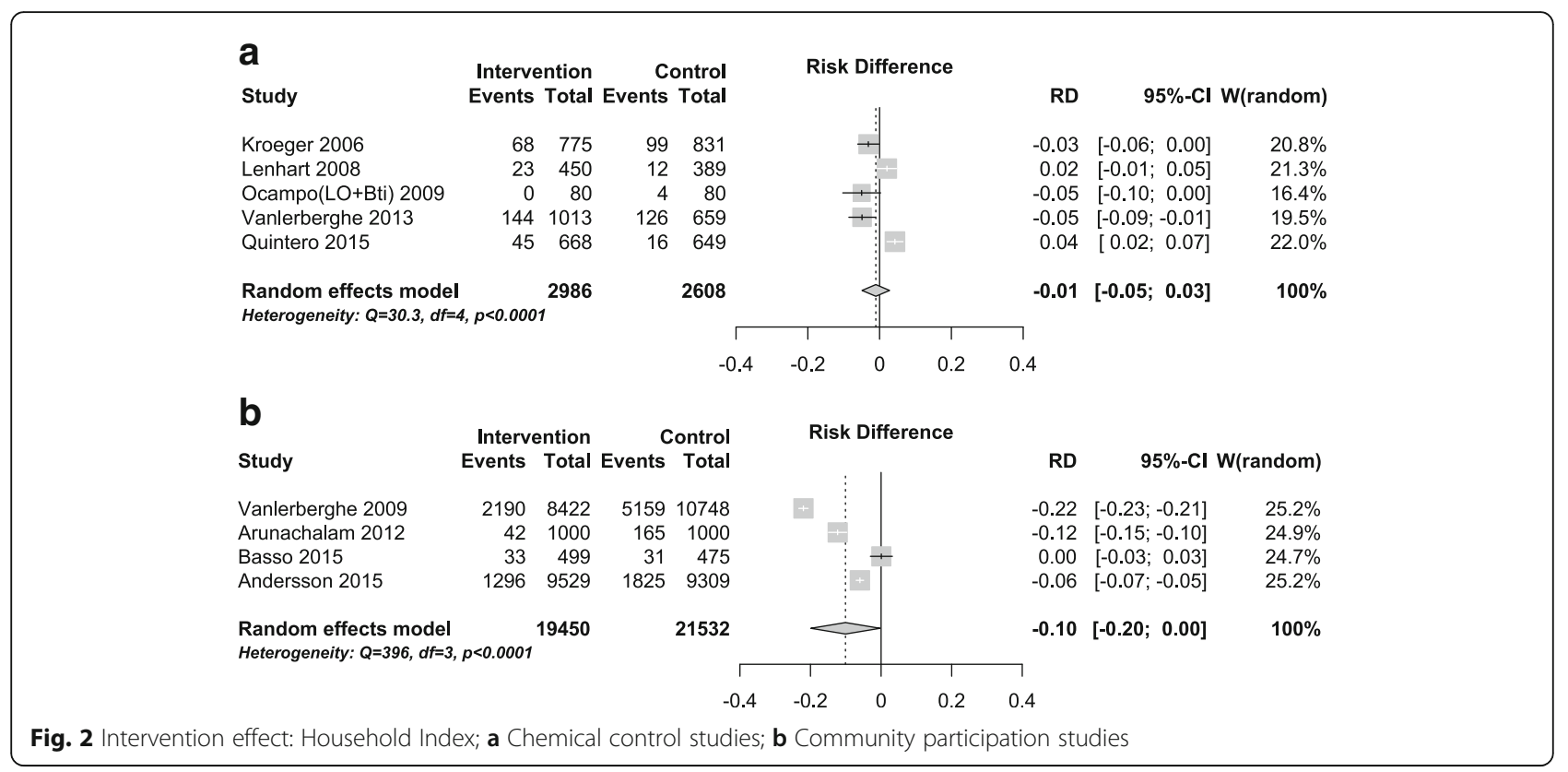

\section{Discussion}

This systematic review and meta-analysis of 18 CRCTs published between 2002 and 2015 suggests that community mobilisation programmes are an effective intervention to reduce Aedes aegypti entomological indices.

An earlier systematic review by Erlanger and colleagues included multiple types interventions (chemical, biological, and community-based), concluding that integrated interventions including community involvement were the most effective [15]. Ballenger-Browning and Elder concluded that the evidence base was not good enough to draw conclusions [17]. Our findings are similar to those reported by Bowman in 2016, where community based interventions for dengue vector control showed higher impact than those using insecticidetreated curtains [25]. The four CRCTs of community participation in our review reported continuation of government vector control (usually temephos application and area fumigation) in both intervention and control sites $[46,47,52,53]$. The observed decreases in the HI, $\mathrm{CI}$ and BI represent added effectiveness from community mobilisation.

Only one CRCT of a biological control intervention met our inclusion criteria. The Thailand trial of copepods or Bti, together with some community activation, reported no significant difference in entomological indices between intervention and control communities at six months [44]. Biological control is attractive as it avoids chemical contamination to the environment, but it may have operational limitations for large scale application. Erlanger noted that biological control has only been tested on a small scale [15] and Bowman noted the clear need for adequately sized CRCTs of biological control interventions for dengue prevention [25].

\section{Strengths and weaknesses}

Unlike earlier systematic reviews [14-25], our review only included CRCTs. Our meta-analysis required data for calculating classic Aedes aegypti entomological indices. This limited the number of studies eligible to be included but it meant that the quality of the included studies was relatively good. None of the 18 studies included in our systematic review was considered to have a high risk of bias, although 10 had an "unclear" risk of bias, mostly due to lack of information in the reports. Other limitations of our meta-analysis are the heterogeneity of intervention duration, the small number of clusters in some of the studies, and the variable cluster size, all of which could affect the intervention effectiveness estimates. The sensitivity analysis, however, showed stability of the global effectiveness estimates.

The grouping of different kinds of interventions together into the broad categories of chemical interventions, biological interventions, and community mobilisation interventions in the meta-analysis could lead to the effectiveness of a particular intervention being under-estimated because it is over-shadowed by poor performance of other interventions in the same broad group. We do not believe this is likely in our study. The four community mobilisation studies all showed positive impacts, albeit of varying magnitude. And among the five chemical intervention trials, three were of treated window and door curtains or nets, and one was of treated bednets, with only one being a different type of intervention (lethal ovitraps). 


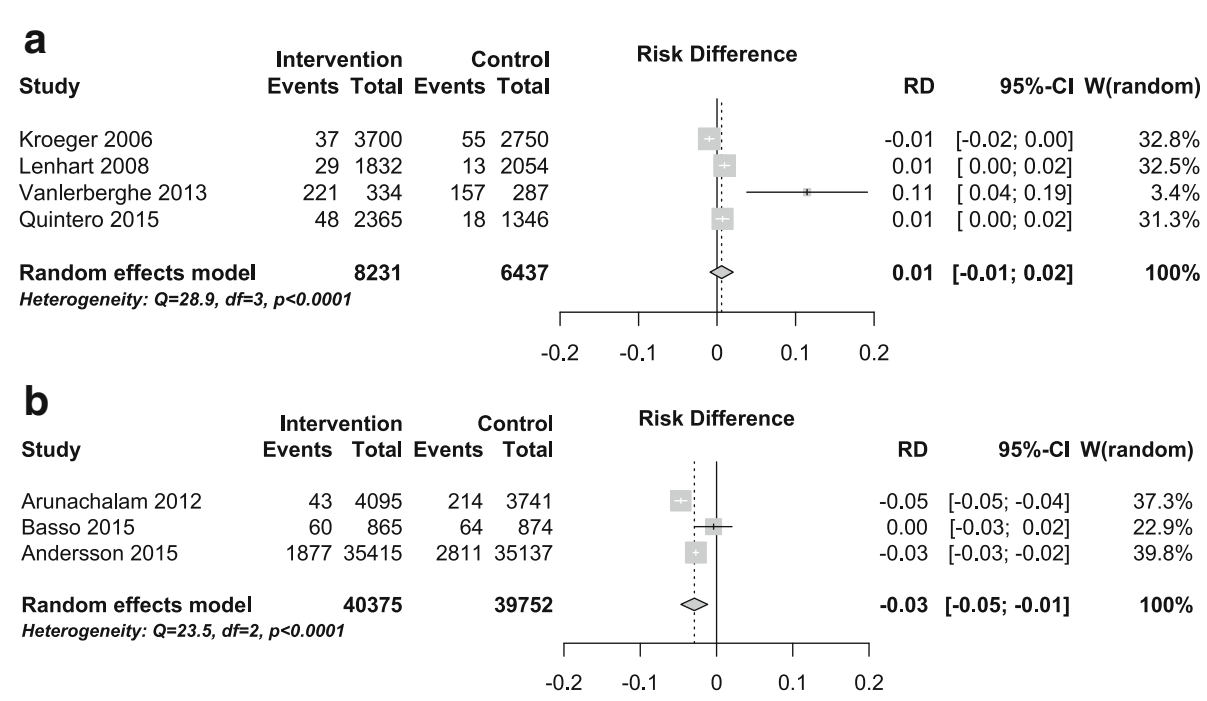

Fig. 3 Intervention effect: Container Index. a Chemical control studies; b Community participation studies

We were not able to include the main chemical control methods used in government Aedes aegypti control programmes - temephos in domestic water containers and peri-domestic insecticide spraying - in our metaanalysis because we did not identify any CRCTs with details of impact on entomological indicators. In the descriptive review, we included one CRCT of temephos use, with no significant impact on entomological indices [36], and a CRCT that studied both and education programme and ultra-low volume malathion spraying and temephos application, and found that the ULV spraying reduced the effectiveness of the educational intervention [45].
Table 3 and Figs. 2-4 are based on the last measurement point comparing intervention and control sites in each trial. It is possible that this missed some useful impact for some of the interventions. In the trials reported by Lenhart et al. [38] and Vanlerberghe et al. [41] the difference between intervention and control clusters was greater in earlier measurements than later measurements; the authors attributed this to spill-over effects or reduced coverage of the treated materials over time.

\section{Public health implications}

Cluster trials, assessing community effectiveness, unlike household or container based trials, take account of

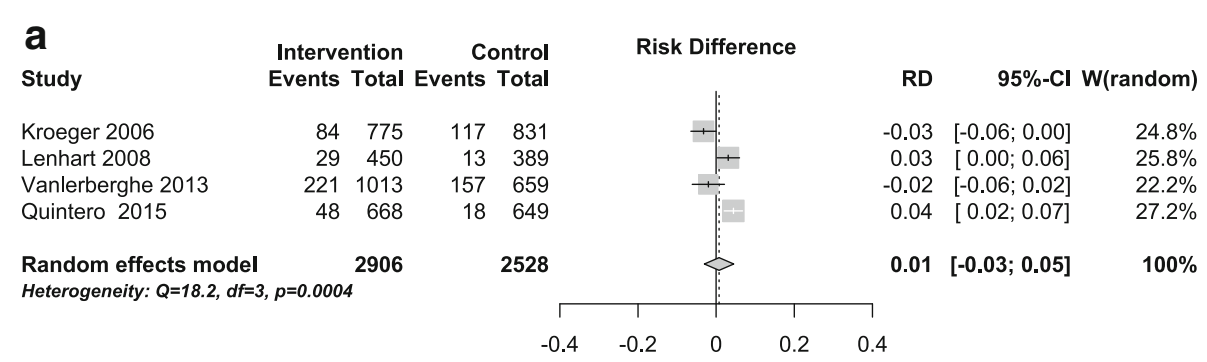

b
Study

Vanlerberghe 2009

Arunachalam 2012

Basso 2015

Andersson 2015

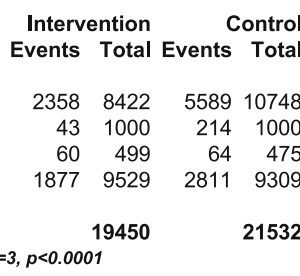

Random effects model

Heterogeneity: $Q=259.8, d f=3, p<0.0001$
Risk Difference

\section{al}

48

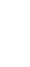
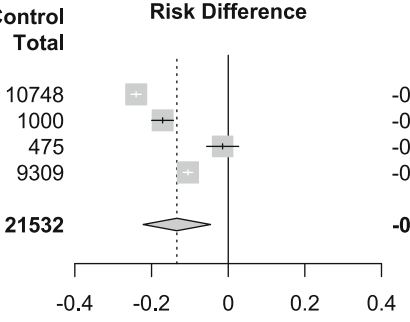

Fig. 4 Intervention effect: Breteau Index. a Chemical control studies; b Community participation studies 
community level dynamics. In this real life setting, our review shows chemical control was less effective than community mobilisation, for all three entomological indices.

Depositing temephos in water storage containers is the mainstay of most centrally managed Aedes aegypti control programmes in Latin America and elsewhere [6]. A recent systematic review of the effectiveness of temephos for dengue vector control concluded there was evidence of impact on entomological indices of Aedes aegypti when temephos use was evaluated as a single intervention; effectiveness varied considerably depending on factors such as frequency and method of application and usually did not persist for more than three months. The effect of temephos was less in studies where temephos was part of a combined intervention, as it is almost everywhere in Aedes aegypti control programmes [21]. Most of the studies in the temephos review by George et al. were not CRCTs [21]. The single CRCT of the use of temephos alone included in our systematic review reported no impact of temephos on entomological indices [36]. In Guatemala, the use of temephos together with deltamethrin treated window and door nets had an impact on some, but not all, entomological indices [40].

Outside the research context, Aedes aegypti control almost everywhere implies complex interventions and cluster dynamics. Community mobilisation implies changes in human attitudes and behaviour, which in turn has multiple effects: people might be motivated to control breeding sites and to cover water containers, to work together on communal vector breeding sites like cemeteries, and they might also be motivated to remove pesticide from water containers. From a centrally managed programme, it would be difficult to foresee the exact mix of interventions to suit every community. Centrally managed awareness and education programmes are thus a weak basis to achieve community commitment to and ownership of interventions. Sustainable community engagement includes local evaluation of evidence and co-designing interventions that best suit their local conditions and culture [54]. This community authorship, rather than interventions being imposed or advised from outside, seems to underwrite the success of the Camino Verde intervention in Mexico and Nicaragua [55].

The cost implications of multi-faceted programmes for vector control need further study. Countries using temephos and insecticide spraying as key elements of national vector control programmes already carry the expense of centralised programming and logistical structures, and the vertical management and huge numbers of local personnel required to achieve monthly or bimonthly household visits. These countries are paying for vector control that, judging by the relentless increase in dengue risk and recent explosive zika and chikungunya epidemics, does not work very well. A central concern in adding community engagement efforts is how much this would add to effectiveness and acceptability, in relation to the added cost. The cost of adding community engagement might also be offset if it helped to support uptake of a dengue vaccine as that becomes a real public health option.

\section{Conclusion}

The implications of our review for dengue vector control are clear. The most consistently effective intervention was community mobilization. Governments that rely on chemical control of Aedes aegypti should consider adding community mobilization to their prevention efforts.

More well-conducted CRCTs of complex interventions, including those with biological control, are needed to provide evidence of real life impact. Future trials of interventions of all kinds should include measurement of impact on dengue infection as well as on entomological indices.

\section{Abbreviations}

95\%Cl: 95\% confidence intervals; BI: Breteau index; Cl: Container index; HI: Household index; PHI: Pupae per household index; PPI: Pupae per person index; RD: Risk difference; SEPA: Socialisation of evidence for participatory action

\section{Acknowledgements \\ We are grateful to Francisco Laucirica who translated the original Spanish manuscript into English. \\ Funding \\ The UBS Optimus Foundation Funding provided funding for publication of this manuscript.}

\section{Availability of data and materials}

No additional data available.

\section{Authors' contributions}

VA and EN conceived and designed the review. VA, SP, EN, AM and NB interpreted the data and wrote the manuscript. In addition, VA and LA devised the search strategy, screened titles, abstracts and full texts, applied inclusion and exclusion criteria, performed data extraction, quality appraisal and checked data extraction. VA undertook the statistical analysis. NA provided technical oversight and contributed to the final manuscript. All authors read and approved the final manuscript.

\section{Competing interests \\ The authors declare they have no competing interests.}

Consent for publication

Not applicable.

Ethics approval and consent to participate not applicable.

\section{About this supplement}

This article has been published as part of BMC Public Health Volume 17 Supplement 1, 2017: The Green Way to Aedes aegypti mosquito control: aspects and implications of the Camino Verde trial in Mexico and Nicaragua. The full contents of the supplement are available online at https:// bmcpublichealth.biomedcentral.com/articles/supplements/volume-17supplement-1\&\#13 


\section{Author details}

'Centro de Investigación de Enfermedades Tropicales (CIET), Universidad Autónoma de Guerrero, Acapulco, Guerrero, Mexico. ${ }^{2}$ Unidad Académica de Matemáticas, Universidad Autónoma de Guerrero, Chilpancingo, Guerrero, Mexico. ${ }^{3}$ Department of Family Medicine, McGill University, Montreal, Canada.

\section{Published: 30 May 2017}

\section{References}

1. Bhatt S, Gething PW, Brady OJ, Messina JP, Farlow AW, Moyes $C L$, et al. The global distribution and burden of dengue. Nature. 2013;496:504-7.

2. Sanofi Pasteur: Dengvaxia, world's first dengue vaccine, approved in Mexico. 2015. http://www.sanofipasteur.com/en/articles/dengvaxia-world-s-firstdengue-vaccine-approved-in-mexico.aspx. Accessed 1 May 2017.

3. Statement by the dengue vaccine initiative on the Philippines regulatory approval of Sanofi Pasteur's dengue vaccine, Dengvaxia. 2015. http://www. sabin.org/updates/pressreleases/statement-dengue-vaccine-initiativephilippines-regulatory-approval-sanofi. Accessed 1 May 2017.

4. Sanofi Pasteur: Dengvaxia first denque vaccine, approved in Brazil. 2015. http://www.sanofipasteur.com/en/articles/Dengvaxia-First-Dengue-VaccineApproved-in-Brazil.aspx. Accessed 1 May 2017.

5. Ooi E, Goh K, Gubler D. Dengue prevention and 35 years of vector contro in Singapore. Emerg Infect Dis. 2006;12(6):887-93.

6. World Health Organization. Dengue: Guidelines for diagnosis, treatment, prevention and control. Geneva: World Health Organization; 2009. http:// www.who.int/tdr/publications/documents/dengue-diagnosis.pdf. Accessed 1 May 2017.

7. Haug CJ, Kieny MP, Murgue B. Perspective. The Zika challenge. N Engl J Med. 2016;374:1801-3.

8. Staples JE, Breiman RF, Powers AM. Chikungunya fever: an epidemiological review of a re-emerging infectious disease. Clin Infect Dis. 2009;49:942-8.

9. Weaver SC, Lecuit M. Chikungunya virus and the global spread of a mosquito-borne disease. N Engl J Med. 2015;372:1231-9.

10. Petersen LR, Jamieson DJ, Powers AM, Honein MA. Zika virus. N Engl J Med. 2016;374:1552-63.

11. Barnett ED. Yellow fever: epidemiology and prevention. Clin Infect Dis. 2007; 44:850-6.

12. World Health Organisation. Zika. Strategic response framework and joint operations plan. January-June 2016. WHO/ZIKV/SRF/16.1. http://apps.who. int/iris/bitstream/10665/204420/1/ZikaResponseFramework_JanJun16_eng. pdf?ua=1. Accessed 1 May 2017.

13. World Health Organisation. Zika virus outbreak global response. Interim report, May 2016. WHO/ZIKV/SRF/16.2. http://apps.who.int/iris/bitstream/ 10665/207474/1/WHO_ZIKV_SRF_16.2_eng.pdf?ua=1. Acessed 1 May 2017.

14. Heintze C, Velazco-Garrido M, Kroeger A. What do community-based dengue control programmes achieve? A systematic review of published evaluations. Trans R Soc Trop Med Hyg. 2007;101:317-25.

15. Erlanger TE, Keiser J, Utzinger J. Effect of dengue vector control interventions on entomological parameters in developing countries: a systematic review and meta-analysis. Med Vet Entomol. 2008;22(3):203-21.

16. Pilger D, De Maesschalck M, Horstick O, San Martin J. Denque outbreak response: documented effective interventions and evidence gaps. TroplKA 1. TropIKA.net. http://journal.tropika.net/pdf/tropika/v1n1/a02v1n1.pdf. Accessed 1 May 2017.

17. Ballenger-Browning KK, Elder JP. Multi-modal Aedes aegypti mosquito reduction interventions and dengue fever prevention. Tropical Med Int Health. 2009;14:1542-51.

18. Esu E, Lenhart A, Smith L, Horstick O. Effectiveness of peridomestic space spraying with insecticide on dengue transmission; systematic review. Tropical Med Int Health. 2010;15(5):619-31.

19. Al-Muhandis N, Hunter $P$. The value of educational messages embedded in a community-based approach to combat denque fever: A systematic review and meta regression analysis. PLoS Negl Trop Dis. 2011;5(8):e1278.

20. Boyce R, Lenhart A, Kroeger A, Velayudhan R, Roberts B, Horstick O. Bacillus thuringiensis israelensis (Bti) for the control of dengue vectors: systematic literature review. Tropical Med Int Health. 2013;18(5):564-77.

21. George L, Lenhart A, Toledo J, Lazaro A, Han WW, Velayudhan R, et al. Community-effectiveness of temephos for dengue vector control: a systematic literature review. PLoS Negl Trop Dis. 2015;(9, 9):e0004006.
22. Han W, Lazaro A, McCall P, George L, Runge-Ranzinger S, Toledo J, et al. Efficacy and community effectiveness of larvivorous fish for dengue vector control. Tropical Med Int Health. 2015;20(9):1239-56.

23. Lazaro A, Han W, Manrique-Saide P, George L, Velayudhan R, Toledo J, et al. Community effectiveness of copepods for dengue vector control: systematic review. Tropical Med Int Health. 2015;20(6):685-706.

24. Lima EP, Goulart MO, Rolim Neto ML. Meta-analysis of studies on chemical, physical and biological agents in the control of Aedes aegypti. BMC Public Health. 2015;15:858

25. Bowman L, Donegan S, McCall P. Is dengue vector control deficient in effectiveness or evidence?: Systematic review and meta-analysis. PLoS Negl Trop Dis. 2016;10(3):e0004551.

26. World Health Organisation. Integrated vector management. http://www. who.int/neglected_diseases/vector_ecology/ivm_concept/en/. Accessed 1 May 2017.

27. World Health Organization. Dengue: control strategies. http://www.who.int/ denguecontrol/control_strategies/en/. Accessed 1 May 2017.

28. Higgins JPT, Green S (editors). Cochrane Handbook for Systematic Reviews of Interventions Version 5.1.0 [updated March 2011]. The Cochrane Collaboration, 2011. Available from www.handbook.cochrane.org Accessed 1 May 2017

29. Egger M, Smith GD, Phillips AN. Meta-analysis: principles and procedures. BMJ. 1997:315:1533-7.

30. Andersson N, Mitchell S. Epidemiological geomatics in evaluation of mine risk education in Afghanistan: introducing population weighted raster maps. Int J Health Geogr. 2006;5:1.

31. R Core Team. R: A language and environment for statistical computing. Vienna: R Foundation for Statistical Computing; 2013. http://www.r-project. org/. Accessed 1 May 2017.

32. DerSimonian R, Laird N. Meta-analysis in clinical trials. Control Clin Trials. 1986;7:177-88.

33. L'abbé KA, Detsky AS, O'Rourke K. Meta-analysis in clinical research. Ann Intern Med. 1987;107:224-33.

34. Steichen TJ. Tests for publication bias in meta-analysis. Stata Tech Bull. 1998; 41:9-15

35. Begg CB, Mazumdar M. Operating characteristics of a rank correlation test for publication bias. Biometrics. 1994;50:1088-101.

36. Camargo-Donalisio MR, Ferreira-Leite O, Caporale-Mayo R, Pinheiro-Alves MJC, de Souza A, Rangel O, et al. Use of temephos for control of field population of Aedes aegypti in Americana São Paulo, Brazil. Dengue Bull. 2002;26:173-7.

37. Kroeger A, Lenhart A, Ochoa M, Villegas E, Levy M, Alexander N, et al. Effective control of dengue vectors with curtains and water container covers treated with insecticide in Mexico and Venezuela: cluster randomised trials. BMJ. 2006:332:1247-52.

38. Lenhart A, Orelus N, Maskill R, Alexander N, Streit T, McCall PJ. Insecticidetreated bednets to control dengue vectors: preliminary evidence from a controlled trial in Haiti. Tropical Med Int Health. 2008;13(1):56-67.

39. Ocampo CB, González C, Morales CA, Pérez M, Wesson D, Apperson CS. Evaluation of community-based strategies for Aedes aegypti control inside houses. Biomedica. 2009:29:282-97.

40. Rizzo N, Gramajo R, Cabrera-Escobar M, Arana B, Kroeger A, Manrique-Saide $P$, et al. Dengue vector management using insecticide treated materials and targeted interventions on productive breeding-sites in Guatemala. BMC Public Health. 2012:12:931.

41. Vanlerberghe $V$, Trongtokit $Y$, Jirarojwatana $S$, Jirarojwatana R, Lenhart A, Apiwathnasorn $C$, et al. Coverage-dependent effect of insecticide-treated curtains for dengue control in Thailand. AmJTrop Med Hyg. 2013;89(1):93-8.

42. Quintero J, García-Betancourt T, Cortés S, García D, Alcalá L, González-Uribe $C$, et al. Effectiveness and feasibility of long-lasting insecticide-treated curtains and water container covers for dengue vector control in Colombia: a cluster randomized trial. Trans R Soc Trop Med Hyg. 2015;109:116-25.

43. Che-Mendoza A, Guillermo-May G, Herrera-Bojórquez J, Barrera-Pérez M, Dzul-Manzanilla F, Gutierrez-Castro C, et al. Long-lasting insecticide-treated house screens and targeted treatment of productive breeding-sites for dengue vector control in Acapulco, Mexico. Trans R Soc Trop Med Hyg. 2015;109:106-15.

44. Kittayapong P, Thongyuan S, Olanratmanee P, Aumchareoun W, Koyadun S, Kittayapong R, et al. Application of eco-friendly tools and eco-biosocial strategies to control dengue vectors in urban and peri-urban settings in Thailand. Pathog Glob Health. 2012;106(8):446-54. 
45. Espinoza-Gómez F, Hrnández-Suárez M, Coll-Cárdenas R. Educational campaign versus malathion spraying for the control of Aedes aegypti in Colima. Mex J Epidemiol Community Health. 2002;56:148-52.

46. Vanlerberghe V, Toledo ME, Rodríguez M. Gomez D, Baly A, Benitez JR, et al. Community involvement in dengue vector control: cluster randomised trial. BMJ 2009;12(1):41-47.

47. Arunachalam N, Kishore Tyagi B, Samuel M, Krishnamoorthi R, Manavalan R, Chandra TS. Community-based control of Aedes aegypti by adoption of ecohealth methods in Chennai City, India. Pathogens Glob Health. 2012;106(8): 488-96.

48. Abeyewickreme W, Wickremasinghe AR, Karunatilake K, Sommerfeld J, Krogel A. Community mobilization and household level waste management for dengue vector control in Gampaha district of Sri Lanka; an intervention study. Pathogens Glob Health. 2012;106(8):479-87.

49. Castro M, Sánchez L, Pérez D, Carbonell N, Lefèvre P, Vanlerberghe V, et al. A community empowerment strategy embedded in a routine dengue vector control programme: a cluster randomised controlled trial. Trans $\mathrm{R}$ Soc Trop Med Hyg. 2012;106:315-21.

50. Caprara A, De Oliveira-Lima J, Rocha-Peixoto A, Vasconcelos-Mota C, SoaresNobre J, Sommerfeld J, et al. Entomological impact and social participation in dengue control: a cluster randomized trial in Fortaleza, Brazil. Trans R Soc Trop Med Hyg. 2015;109:99-105.

51. Michell-Foster K, Beltrán E, Breilh J, Spiegel J, Arichabala A, Ordóñez T, et al. Integrating participatory community mobilization processes to improve dengue prevention: an eco-bio-social scaling up of local success in Machala, Ecuador. Trans R Soc Trop Med Hyg. 2015;109:126-33.

52. Basso C, García E, Romero S, González C, Lairihoy R, Roche I, et al. Improved dengue fever prevention through innovative intervention methods in the city of Salto, Uruguay. Trans R Soc Trop Med Hyg. 2015;109:134-42.

53. Andersson N, Nava-Aguilera E, Arosteguí J, Morales-Perez A, Suaso-Laguna $\mathrm{H}$, Legorreta-Soberanis J, et al. Evidence based community mobilisation for dengue prevention in Nicaragua and Mexico (Camino Verde, the Green Way): cluster randomized controlled trial. BMJ. 2015;351:h3267.

54. McLeroy K, Norton B, Kegler M, Burdine J, Sumaya C. Community-Based interventions. Am J Public Health. 2003;93(4):529-33.

55. Morales-Pérez A, Nava-Aguilera E, Legorreta-Soberanis J, Balanzar-Martínez A, Serrano-de los Santos FR, Ledogar RJ, et al. Which Green Way: description of the intervention for mobilising against Aedes aegypti under difficult security conditions in southern Mexico. BMC Pubic Health. 2017;17(Suppl 1):S14.

\section{Submit your next manuscript to BioMed Central and we will help you at every step:}

- We accept pre-submission inquiries

- Our selector tool helps you to find the most relevant journal

- We provide round the clock customer support

- Convenient online submission

- Thorough peer review

- Inclusion in PubMed and all major indexing services

- Maximum visibility for your research

Submit your manuscript at www.biomedcentral.com/submit

C Biomed Central 